\title{
Application of DIP to Detect Power Transformers Axial Displacement and Disk Space Variation using FRA Polar Plot Signature

\author{
Aljohani, O. and Abu-Siada, A
}

\begin{abstract}
While frequency response analysis (FRA) technique has been successfully used to assess the mechanical integrity of active parts within power transformers, it still exhibits some drawbacks including its inability to detect incipient and minor winding deformations and the requirement for an expert to analyze the results. Although several papers have investigated the impact of various faults on the transformer FRA signature, no attempt was made to automate and improve the fault detection accuracy of the current technique. The main contribution of this paper is the presentation of a new approach for FRA technique through incorporating the magnitude and phase angle plots that can be measured using any commercial frequency response analyzer into one polar plot. In contrary with the current industry practice that only relies on the magnitude of the measured FRA signature for fault identification and quantification, the proposed polar plot that comprises more features than the magnitude plot will facilitate the use of digital image processing (DIP) techniques to improve the detection accuracy, standardize and automate the FRA interpretation process. In this regard, 3D models for two 3-phase power transformers of different ratings, sizes and windings structures are modelled using finite element analysis (FEA) technique to simulate various levels of axial displacement (AD) and disk space variation (DSV) at different locations of the transformer windings. Impact of minor fault levels on the proposed polar plot signature is investigated through the application of various DIP techniques. Simulation results are validated through practical measurements on a scaled-down transformer. Results show that the proposed polar plot along with DIP technique is able to detect minor fault levels of AD and DSV with high accuracy.
\end{abstract}

Index Terms - Transformer frequency response analysis, Digital image processing, Axial displacement, Disk space variation.

\section{INTRODUCTION}

$\mathrm{P}$ OWER transformer is one of the key assets in the electricity grid that should be carefully monitored in order to maintain the reliability of transmission and distribution networks. Among the condition monitoring and fault diagnosis techniques currently used by industry to assess the health condition of power transformer, frequency response analysis (FRA) has been widely accepted as a reliable tool to detect internal transformer mechanical deformations that could result due to short circuit faults or transformer oil combustible gas explosions [1,2]. The FRA technique was developed based on the fact that all transformer elements including active parts and insulation system can be modelled as a cascaded network of resistive and inductive/capacitive reactance components [3]. As these components are frequency dependent, its value will change in a unique way due to any particular variation in the physical structure of the transformer[4]. FRA can detect this change thorough taking the investigated transformer out-of-service and applying a sweep frequency voltage of low amplitude to one terminal of a transformer winding and measuring the response across the other terminal of the winding with reference to the earthed tank [5]. The measured FRA signature is provided as a magnitude and phase angle plots of the winding impedance, admittance, or transfer function $\left(\mathrm{V}_{\text {out }} / \mathrm{V}_{\text {input }}\right.$ in $\left.\mathrm{dB}\right)$ in a wide frequency range. While the FRA measurement is standardized since the development of various commercial analysers, interpretation of FRA signature still requires a highly specialized personal as there is no interpretation code published and widely accepted yet [6]. This may lead to inconsistent interpretation for the same FRA signature. Furthermore, current FRA technique is not able to detect incipient and minor winding deformations within power transformers. Although a transformer can continue work normally with such minor winding deformation, it is essential to detect and take appropriate maintenance action at early stage due to the progressive nature of such faults to avoid any catastrophic failure to the asset [3]. While many papers investigating the impact of various winding deformations on the conventional FRA magnitude plot can be found in the literature, no attempt has been made to improve its accuracy to detect incipient and minor deformations [5, 7]. A few studies have been conducted in order to ease the interpretation process of the transformer FRA signature through calculating various statistical indicators such as correlation coefficient, standard deviation and the absolute sum of logarithmic error [8, 9]. The correlation coefficient however, may lead to a wrong correlation between the two investigated signatures under certain circumstances and is considered as inadequate parameter for FRA interpretation [9]. On the other hand, standard deviation fails to reflect the information scattered around the low magnitudes of the FRA signature and only the peaks differences of the two investigated signatures will dominate the calculated value which may result in a wrong interpretation outcome $[10,11]$. The absolute sum of logarithmic error (ASLE) was introduced to realize a full logarithmic scaled comparison between two FRA signatures [12]. However the reliability of using ASLE indictor in FRA interpretation has not been accepted yet and it requires further investigation [13]. The key contribution of this paper lies in introducing a new FRA signature for power transformers based on the incorporation of the magnitude and phase angle plots of the measured signal into one polar plot that involves more features than the conventional magnitude plot which is currently used for fault identification. Also, the paper is aimed at utilizing the rapid advancement in digital image processing (DIP) techniques to standardize, automate and enhance the accuracy of the FRA interpretation process. The feasibility of the proposed approach is assessed through the detection of minor fault levels of winding axial displacement (AD) and disk space variation (DSV) faults simulated using finite element analysis (FEA) technique on two 3-phase transformer models of different ratings (10kVA and 40MVA), sizes and winding structures. 
Simulation results are validated through practical laboratory measurements on a scaled-down transformer.

\section{POWER TRANSFORMER MODELLING USING FEA}

FEA is a computerized technique developed to model complicated systems within multi-fields environment to emulate real system operation [14, 15]. Two 3-phase delta-wye transformers of ratings $10 \mathrm{kVA}$ and 40MVA that have different physical dimensions and winding structures are modelled using FEA. The physical dimensions of the two transformers under investigation are illustrated in Fig. 1. The 10kVA transformer (oil natural, air natural (ONAN)-cooled, 11.55/0.412kV) windings are designed in rectangular shape where the high voltage (HV) winding comprises 6 disks with 1134 turns per disk, while the low voltage (LV) winding is modelled as a continuous layer of 140 turns. On the other hand, the windings of the 40MVA transformer (ONAN-cooled, 110/6.6kV) are structured in a circular form. HV winding consists of 10 disks with 1200 turns per disk and the LV winding is made of a singular layer of 200 turns. The insulation system of both transformers is implemented using Kraft paper and mineral oil [16].
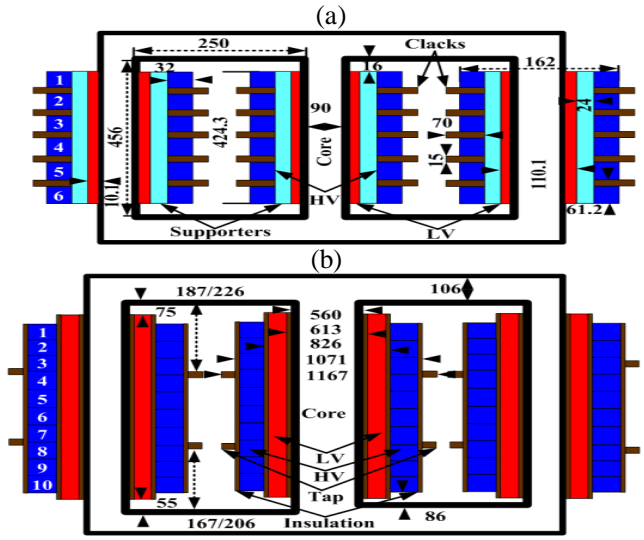

Fig. 1. Transformer schematic diagrams: (a) 10kVA and, (b) 40MVA

The 3D models of both transformers are solved in magnetostatic, electro-static and eddy current solvers using Maxwell equations to extract the inductance, capacitance and resistance matrices of the relevant transformer components which are listed in Table A-I in the Appendix. The methodology used in the calculations is explained in depth in $[17,18]$.

\section{PROPOSED FRA POLAR PLOT SIGNATURE}

The conventional FRA signatures of the two transformer models are obtained by connecting a low-amplitude AC voltage source $(10 \mathrm{~V})$ of a variable frequency $\left(\mathrm{V}_{\mathrm{in}}\right)$ at one terminal of the transformer winding, and measuring the response signal at the other terminal of the same winding $\left(\mathrm{V}_{\text {out }}\right)$ while other phases are left open circuited. The transfer function (TF) of each phase within the HV and LV windings of the two transformers is calculated in a wide frequency range (up to $1 \mathrm{MHz}$ ) and plotted as magnitude (in $\mathrm{dB}$ ) and phase angle (in degrees) as shown in Figs. 2 and 3, respectively. At low frequency range and due to the fact that flux penetration to the core is significant within this range, the signature is characterized by the transformer inductive components while at higher frequency range the distributed capacitive components tend to shunt the winding inductance as can be shown in the phase angle that fluctuates between $\pm 90^{\circ}$. The FRA signature should be measured for new transformers prior commencement into service to compare any future signature with. Any variation in the FRA signature indicates a fault within the transformer. If the finger print is not available for old transformers, comparing the transformer FRA signature with the signature of sister transformer is to be adopted. Phase to phase comparison may also be used to detect any variations.
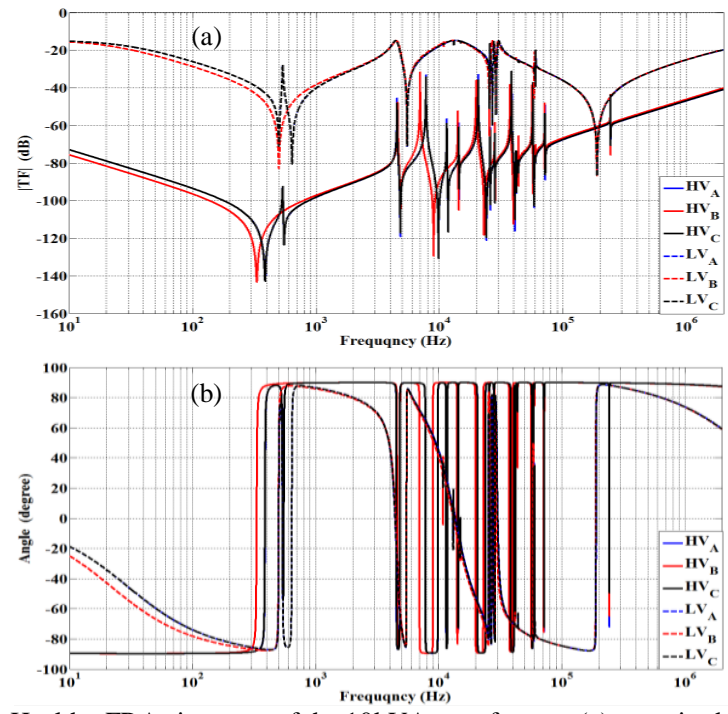

Fig. 2. Healthy FRA signature of the 10kVA transformer: (a) magnitude and (b) phase angle
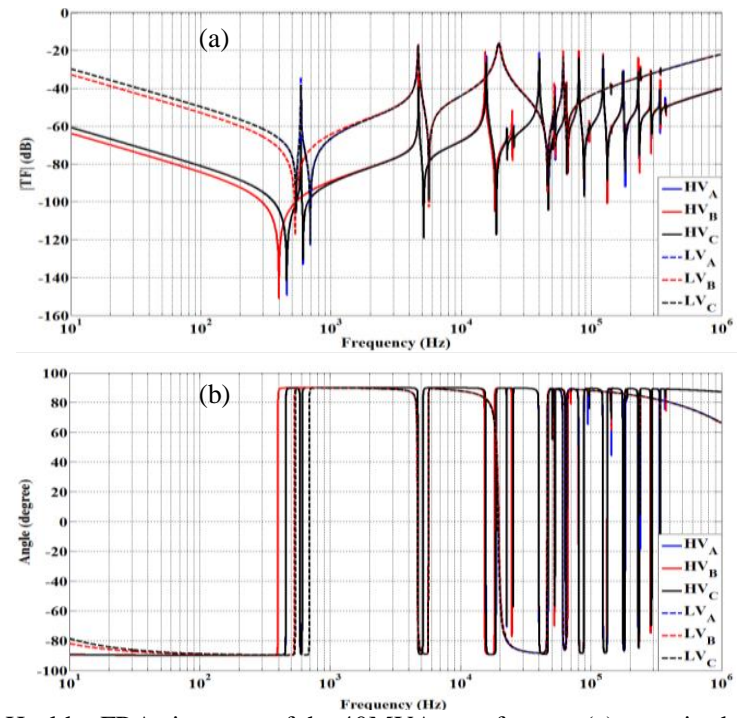

Fig. 3. Healthy FRA signature of the 40MVA transformer: (a) magnitude and (b) phase angle

As can be seen in Figs. 3 and 4, the 3-phase FRA signatures of the $\mathrm{LV}$ and $\mathrm{HV}$ windings are identical except for the middle limb (phase B) that tends to the left in the frequency range less than $10 \mathrm{kHz}$ which is attributed to the slight difference in the magnetic flux of the middle limb compared to the other two limbs (phases A and C). Although the FRA signature trend of the 10kVA and 40MVA transformers is similar, slight differences in the resonance peaks of the two transformers can be noticed, which may be attributed to the difference in transformer ratings, sizes and windings structures. In spite of the fact that all commercial frequency response analysers provide the FRA signature as magnitude and phase angle, only magnitude plot is currently used to detect various mechanical 
faults within the transformer. The new FRA signature proposed in this paper relies on incorporating the magnitude and phase angle of the measured FRA signature in one polar plot as shown in Fig. 4. The proposed polar plot comprises most of the features of the measured signal and can facilitate the application of DIP techniques. Each point on the polar plot involves three specific details about the measured FRA signature; the magnitude $r$ which is measured from the origin, the phase angle $\theta$ that is measured with respect to the $\mathrm{x}$-axis at a particular frequency value $f$ which varies from $10 \mathrm{~Hz}$ to $1 \mathrm{MHz}[19,20]$. In Fig. 4 (a), any point $a_{i}$ on the polar plot signature is a function of $\left(f_{i}, \boldsymbol{r}_{i}, \theta_{i}\right)$.

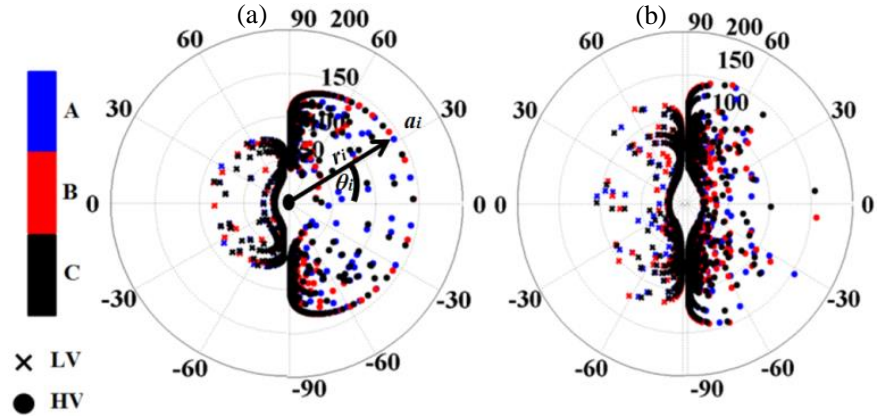

Fig. 4. Healthy transformer polar plot signatures: (a) 10kVA and (b) 40MVA

Fig. 4 reveals that the polar plot signatures of each winding within the 10kVA and 40MVA transformers are almost identical in their geometrical structures. However, the polar plot signatures of the HV windings are characterized by larger entire area and longer contour than that of the LV windings which may be attributed to the difference in winding design and equivalent electrical parameters as can be observed from Table A-I in the Appendix.

\section{DIGITAL IMAGE PROCESSING TECHNIQUES}

Digital image processing (DIP) aims at improving the interpretation of pictorial information based on developed computer algorithms [21]. The digital image [A] is represented by a two-dimensional matrix $(M \times N)$ which consists of finite number of digital values (pixels). Any point on the proposed polar plot is represented as $\{a(i, j)\}$, where $|a|$ represents the image intensity at a point which has spatial location of $(i, j)$ with respect to the $(X, Y)$ coordinates.

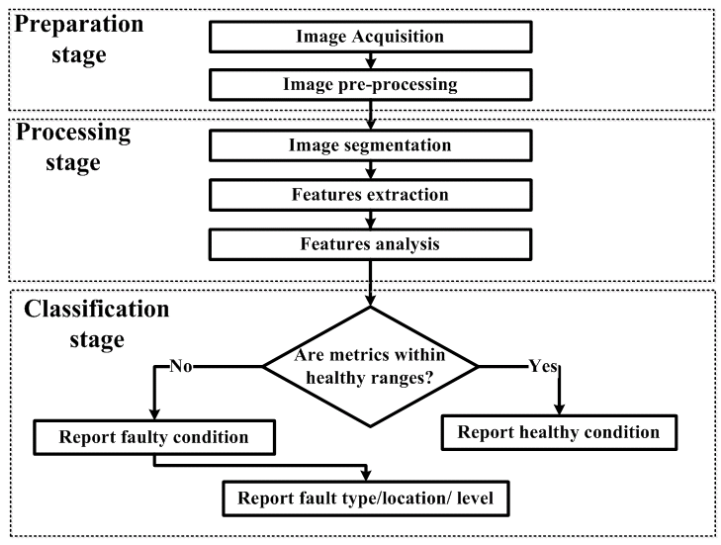

Fig. 5. Flow chart of the proposed DIP technique

An image can be well-described through some unique features such as geometric dimensions, invariant moment and texture analysis that could be extracted from the image using DIP techniques [21-24]. To increase the accuracy of the proposed DIP technique, the aforementioned three features are extracted from the proposed polar plot as per the flow chart in Fig. 5. The proposed DIP technique can be built within commercial frequency response analysers to extract the polar plot data and analyze it. The pre-processing stage is aimed at adjusting image dimension size, colour format and extension type to ease sensing the image in electronic systems [21]. Segmentation process is used to divide the image into several parts to eliminate unwanted effects, such as image noise and background and to obtain the required object within the image using edge detection algorithm such as the improved Canny edge detector $[25,26]$. The detected FRA polar plot is manipulated to extract four geometric dimensions features and 11 combined features of invariant moment and texture analysis techniques [22, 23]. The extracted features are analyzed to calculate three unique metrics; city-block distance (CBD), root mean square (RMS) and image Euclidean distance (IED) [27]. Similar to conventional FRA process, the three metrics are to be calculated for new transformers and considered as a reference dataset for future comparison. The classification stage shown in Fig. 5 is aimed at identifying fault type, level and location within the investigated transformer through comparing polar plot extracted features with the reference dataset [27].

The geometric dimension technique extracts four features from the polar plot image including entire area $\left(g_{l}\right)$, outer contour perimeter $\left(g_{2}\right)$, centroid coordinates $\left(g_{3}\right)$, and the length of minor and major axes of the outer contour $\left(g_{4}\right)$ based on the equations listed in Table A-II in the Appendix [21].

The invariant-moment is a powerful DIP technique as the seven extracted features using this technique are independent on the image scale, rotation or translation [23]. The seven features of the invariant moment technique are measured based on order moment $\left(m_{p q}\right)$, central moment $\left(\mu_{p q}\right)$ and normalized moment $\left(\boldsymbol{\eta}_{p q}\right)$ of the image function $f(x, y)$ as detailed in [23]. The formulas used in calculating invariant moment features are listed in Table A-III in the Appendix.

Texture analysis technique can provide information about the intensity of the investigated polar plot signature. Four texture features are extracted from the processed image including, correlation feature $\left(\tau_{1}\right)$ that measures the correlation between the pixel and its neighbors over the entire image, homogeneity feature $\left(\tau_{2}\right)$ which measures the spatial closeness of the image distribution elements to the diagonal elements, contrast feature $\left(\tau_{3}\right)$ that calculates the contrast between pixel and its neighbor over the entire image, and energy feature $\left(\tau_{4}\right)$ which measures entire image uniformity [22]. Table A-IV in the Appendix lists the equations of the texture analysis technique.

The proposed polar plot along with the above DIP techniques are applied to detect minor fault levels of transformer windings axial displacement and disk space variation as will be elaborated below.

\section{DETECTION OF AD AND DSV}

Transformer winding AD may be resulted due to the imbalanced magnetic forces between the HV and LV windings due to short circuit faults $[2,3,5]$. Due to the progressive nature of $\mathrm{AD}$, incipient fault levels should be detected and a remedial action should be taken as soon as possible to avoid any further consequences. Fig. 6 shows a schematic diagram for the AD fault within phase $\mathrm{A}$ of the $\mathrm{HV}$ and $\mathrm{LV}$ windings of both 
investigated transformers while Fig. 7 shows the configuration for DSV fault within the HV winding of both transformers.

The FRA polar plot signatures of the healthy HV and LV windings of the two investigated transformers (Fig. 4) are manipulated using the developed DIP techniques to extract four geometric dimensions features and 11 combined features of the invariant moment and textures analysis techniques as listed in Tables I and II, respectively. The 4 geometric dimension features are used to calculate CBD metric while the 11 combined features are used to calculate the other two metrics; RMS and IED as below.

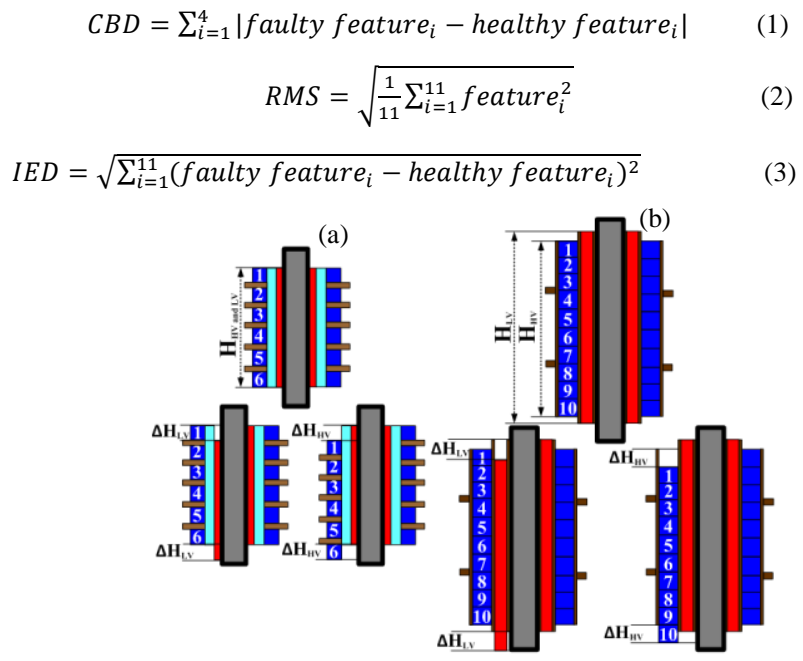

Fig. 6. Front view of healthy and axial displacement fault conditions of $\mathrm{HV}$ and LV windings: (a) 10kVA and (b) 40MVA

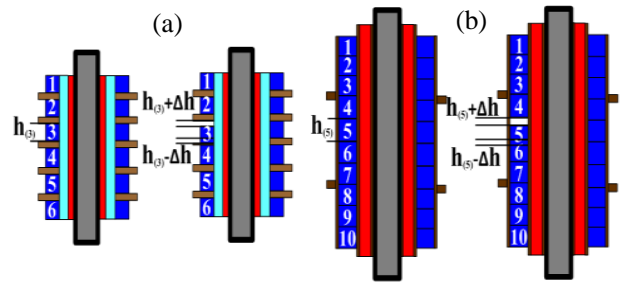

Fig. 7. Front view of health and disk space variation fault conditions of $\mathrm{HV}$ winding: (a) 10kVA and (b) 40MVA

TABLE I

Geometric dimension features of healthy HV and LV windings

\begin{tabular}{|c|c|c|c|c|c|}
\hline \multirow{2}{*}{\multicolumn{2}{|c|}{ Feature }} & \multicolumn{2}{|c|}{$10 \mathrm{kVA}$ transformer } & \multicolumn{2}{|c|}{ 40MVA transformer } \\
\hline & & $\mathrm{HV}$ & LV & HV & LV \\
\hline \multicolumn{2}{|c|}{$\begin{array}{l}g_{1} \\
g_{2}\end{array}$} & 30443 & 9600 & 66091 & 47692 \\
\hline & & 878.70 & 493.15 & 1837.44 & 1473.07 \\
\hline \multirow{3}{*}{$g_{3}$} & $\mathrm{X}$-axis & 358.85 & 339.95 & 673.65 & 673.10 \\
\hline & Y-axis & 289.88 & 289.91 & 612.83 & 560.22 \\
\hline & Major & 374.85 & 221.58 & 834.53 & 642.54 \\
\hline$g_{4}$ & Minor & 109.41 & 59.24 & 199.37 & 127.23 \\
\hline
\end{tabular}

TABLE II

The 11 extracted features for healthy HV and LV windings

\begin{tabular}{|c|c|c|c|c|c|}
\hline \multirow{2}{*}{\multicolumn{2}{|c|}{ Feature }} & \multicolumn{2}{|c|}{$10 \mathrm{kVA}$ transformer } & \multicolumn{2}{|c|}{ 40MVA transformer } \\
\hline & & $\mathrm{HV}$ & LV & $\mathrm{HV}$ & LV \\
\hline 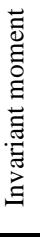 & $\begin{array}{l}\Phi_{1} \\
\Phi_{2} \\
\Phi_{3} \\
\Phi_{4} \\
\Phi_{5} \\
\Phi_{6} \\
\Phi_{7}\end{array}$ & $\begin{array}{c}0.2929 \\
0.0000 \\
0.0016 \\
-0.0054 \\
0.6358 \\
0.0975 \\
0.5423\end{array}$ & $\begin{array}{r}0.4745 \\
0.0000 \\
0.0017 \\
-0.0077 \\
1.7363 \\
0.4392 \\
1.4437\end{array}$ & $\begin{array}{c}0.6207 \\
0.0000 \\
0.0070 \\
-0.0320 \\
3.1864 \\
1.0943 \\
2.5769\end{array}$ & $\begin{array}{c}0.8109 \\
0.0000 \\
0.0072 \\
-0.0377 \\
5.2993 \\
2.3430 \\
4.3172\end{array}$ \\
\hline
\end{tabular}

\begin{tabular}{|c|c|c|c|c|c|}
\hline \multirow{4}{*}{ 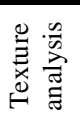 } & $\tau_{1}$ & 0.0779 & 0.0611 & 0.0573 & 0.0521 \\
\hline & $\tau_{2}$ & 1.9611 & 1.9694 & 1.9714 & 1.9740 \\
\hline & $\tau_{3}$ & 1.8222 & 1.8588 & 1.8664 & 1.8789 \\
\hline & $\tau_{4}$ & 0.4876 & 0.5075 & 0.5295 & 0.5301 \\
\hline \multicolumn{2}{|c|}{ RMS } & 0.863598 & 1.091791 & 1.538326 & 2.345671 \\
\hline
\end{tabular}

As shown in Table I, the 4 extracted features representing the physical dimensions of the investigated polar plot of the HV winding are higher than the corresponding features of the LV winding within both transformers. On other hand, Tables II shows that the 11 combined features of the HV winding are less than the corresponding features of the LV winding, except for features $\tau_{1}$ and $\Phi_{2}$ that always equals zero and hence is omitted from upcoming calculations. Tables II and III indicate that all features of the 40MVA transformer are higher than the corresponding features of the $10 \mathrm{kVA}$ transformer.

(a)

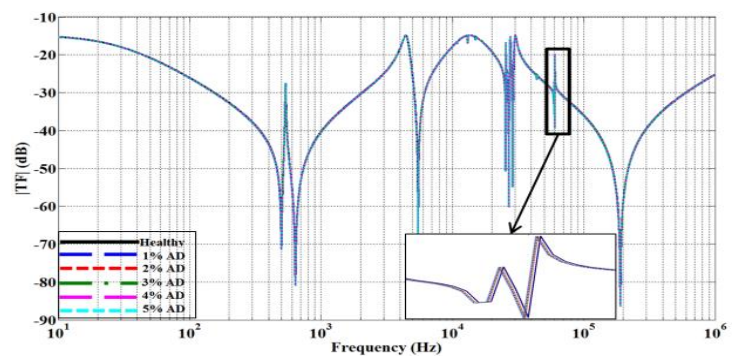

(b)

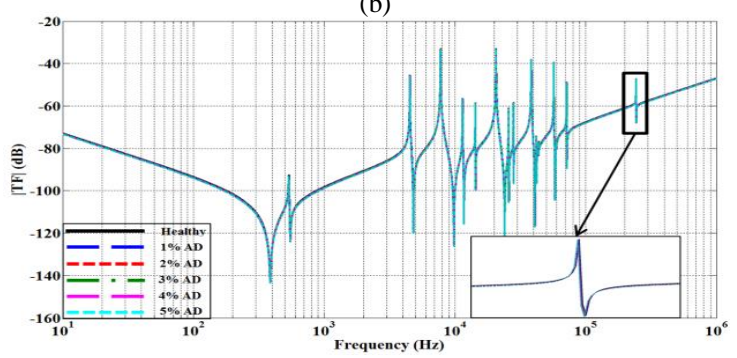

Fig. 8. Impact of AD on the 10kVA FRA signature: (a) LV and (b) HV

Based on previous studies [7, 17, 18], transformer windings mechanical deformations are considered minor if the fault level is within the range $1 \%$ to $5 \%$ whereas above $5 \%$ the fault is considered at moderate or major level.

\section{A. Case study 1: 10kVA transformer}

\section{Axial displacement fault}

Five minor levels (1\% to 5\%) of AD fault within phase A of the $\mathrm{HV}$ and LV windings of the 10kVA transformer are simulated using FEA. The level of $\mathrm{AD}$ fault is defined as:

$$
\% \text { AD Fault level }=\frac{\text { Axial displacement length }(\Delta H)}{\text { Winding height }(H)} \times 100 \%
$$

The impact of $1 \%$ to $5 \%$ of $\mathrm{AD}$ faults on the conventional FRA signature (magnitude of the winding transfer function) of the $10 \mathrm{kVA}$ transformer $\mathrm{HV}$ and LV windings is shown in Fig. 8 which reveals the difficulty to detect such minor faults using conventional FRA approach. In order to overcome this drawback, the proposed FRA polar plot signatures for the same fault levels are obtained as shown in Fig. 9 that are analyzed using the developed DIP techniques to extract various image features as given in Tables III and IV.

(a)

(b) 


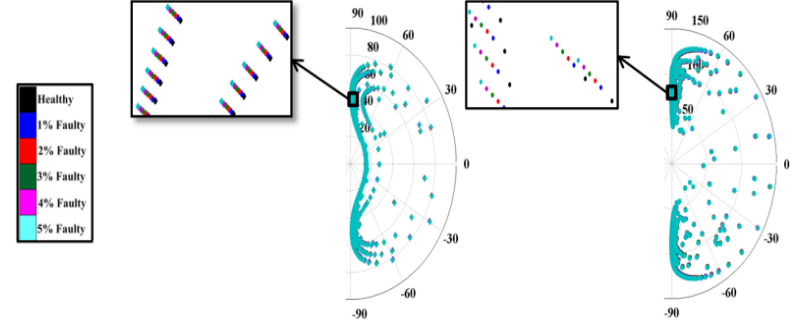

Fig. 9. Impact of $A D$ on the 10kVA polar plot signature: (a) LV and (b) HV

TABLE III

Geometric dimension features of 10kVA transformer AD fault

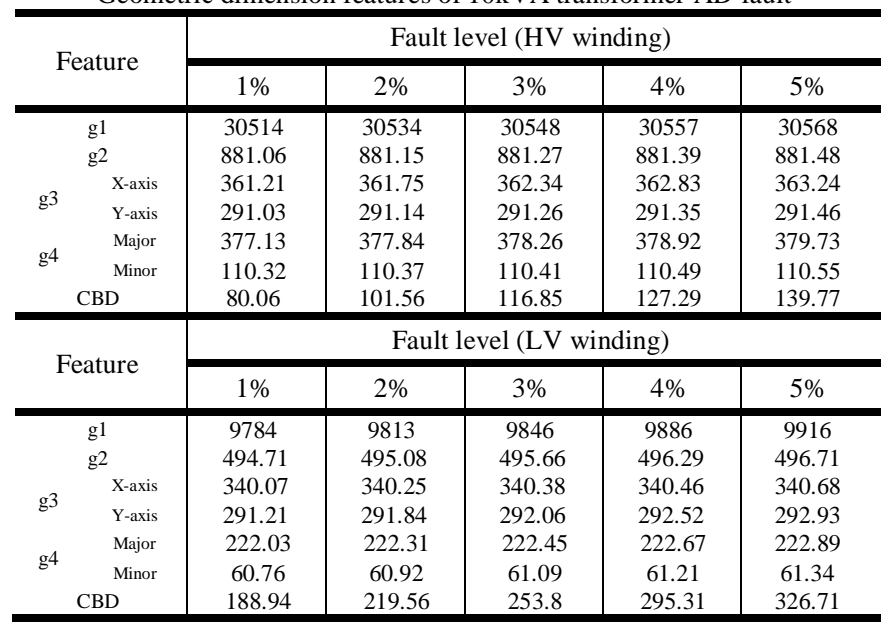

TABLE IV

The 11 extracted features of 10kVA transformer AD fault

\begin{tabular}{|c|c|c|c|c|c|}
\hline \multirow{2}{*}{ Feature } & \multicolumn{5}{|c|}{ Fault level (HV winding) } \\
\hline & $1 \%$ & $2 \%$ & $3 \%$ & $4 \%$ & $5 \%$ \\
\hline 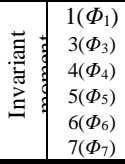 & $\begin{array}{c}0.2684 \\
0.0018 \\
-0.0083 \\
0.6195 \\
0.0948 \\
0.5481\end{array}$ & $\begin{array}{c}0.2651 \\
0.0022 \\
-0.0085 \\
0.6186 \\
0.0934 \\
0.5483\end{array}$ & $\begin{array}{c}0.2627 \\
0.0023 \\
-0.0087 \\
0.6172 \\
0.0921 \\
0.5485 \\
\end{array}$ & $\begin{array}{c}0.2594 \\
0.0024 \\
-0.0088 \\
0.6161 \\
0.0913 \\
0.5487\end{array}$ & $\begin{array}{c}0.2563 \\
0.0025 \\
-0.0089 \\
0.6153 \\
0.0905 \\
0.5489\end{array}$ \\
\hline $\begin{array}{l}8\left(\tau_{1}\right) \\
9\left(\tau_{2}\right) \\
10\left(\tau_{3}\right) \\
11\left(\tau_{4}\right)\end{array}$ & $\begin{array}{l}0.0824 \\
1.9282 \\
1.7895 \\
0.4683 \\
\end{array}$ & $\begin{array}{l}0.0829 \\
1.9275 \\
1.7883 \\
0.4675 \\
\end{array}$ & $\begin{array}{l}0.0835 \\
1.9261 \\
1.7872 \\
0.4655 \\
\end{array}$ & $\begin{array}{l}0.0838 \\
1.9253 \\
1.7864 \\
0.4646 \\
\end{array}$ & $\begin{array}{l}0.0844 \\
1.9226 \\
1.7851 \\
0.4631 \\
\end{array}$ \\
\hline RMS & 0.848081 & 0.847514 & 0.846757 & 0.846234 & 0.845222 \\
\hline IED & 0.058820 & 0.061957 & 0.065626 & 0.068768 & 0.073257 \\
\hline \multirow{2}{*}{ Feature } & \multicolumn{5}{|c|}{ Fault level (LV winding) } \\
\hline & $1 \%$ & $2 \%$ & $3 \%$ & $4 \%$ & $5 \%$ \\
\hline $\begin{array}{l}1\left(\Phi_{1}\right) \\
3\left(\Phi_{3}\right) \\
4\left(\Phi_{4}\right) \\
5\left(\Phi_{5}\right) \\
6\left(\Phi_{6}\right) \\
7\left(\Phi_{7}\right)\end{array}$ & \begin{tabular}{r|}
0.4679 \\
0.0018 \\
-0.0078 \\
1.6813 \\
0.4182 \\
1.4529 \\
\end{tabular} & $\begin{array}{c}0.4661 \\
0.0020 \\
-0.0079 \\
1.6673 \\
0.4172 \\
1.4545 \\
\end{array}$ & $\begin{array}{c}0.4572 \\
0.0021 \\
-0.0081 \\
1.6446 \\
0.4158 \\
1.4572 \\
\end{array}$ & $\begin{array}{c}0.4537 \\
0.0022 \\
-0.0082 \\
1.6371 \\
0.4143 \\
1.4584\end{array}$ & $\begin{array}{c}0.4513 \\
0.0023 \\
-0.0084 \\
1.6257 \\
0.4127 \\
1.4595 \\
\end{array}$ \\
\hline $\begin{array}{l}8\left(\tau_{1}\right) \\
9\left(\tau_{2}\right) \\
10\left(\tau_{3}\right) \\
11\left(\tau_{4}\right) \\
\end{array}$ & $\begin{array}{l}0.0621 \\
1.9689 \\
1.8568 \\
0.5058 \\
\end{array}$ & $\begin{array}{l}0.0624 \\
1.9673 \\
1.8557 \\
0.5043 \\
\end{array}$ & $\begin{array}{l}0.0629 \\
1.9666 \\
1.8535 \\
0.5022 \\
\end{array}$ & $\begin{array}{l}0.0631 \\
1.9651 \\
1.8522 \\
0.5010 \\
\end{array}$ & $\begin{array}{l}0.0634 \\
1.9637 \\
1.8513 \\
0.5004 \\
\end{array}$ \\
\hline RMS & 1.083577 & 1.081200 & 1.077424 & 1.075844 & 1.073861 \\
\hline IED & 0.060020 & 0.073880 & 0.097497 & 0.105916 & 0.117762 \\
\hline
\end{tabular}

Table III reveals that the four geometric dimension features are increasing with the increase in fault level. On the other hand, Table IV shows that while features 1, 5, 6, 9, 10 and 11 decrease with the increase in fault level, features $3,4,7$, and 8 are increasing, and feature 2 (omitted from the Table) is maintained at constant zero level.

The CBD, RMS and IED are calculated based on the extracted features and are depicted in Fig. 10. As can be seen in the figure, the CBD and IED metrics are increasing while the RMS metric is decreasing with the increase in the AD level, which can be used to quantify the fault level. Also, Fig. 10 shows the proposed threshold limits for the three metrics in which a minor $\mathrm{AD}$ is considered if at least one of the three metrics lies between its designated minimum and maximum limits. If any metric exceeds its designated maximum limit, a major $\mathrm{AD}$ may be reported. All calculated metrics should be less than the

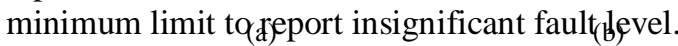
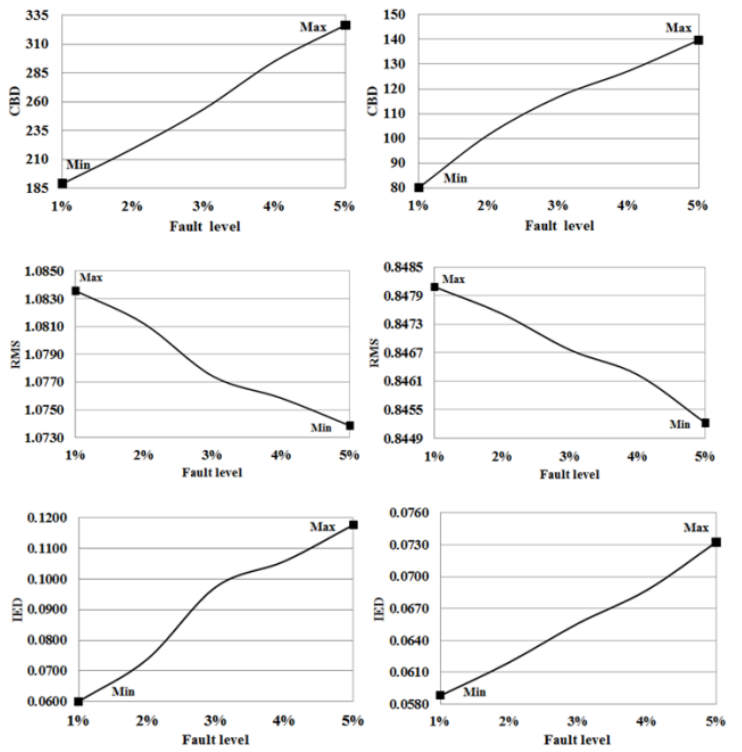

Fig. 10. CBD, RMS and IED trends for 10kVA AD fault: (a) LV and (b) HV

\section{Disk space variation fault}

A disk space variation fault is simulated at different locations within phase A of the HV winding; top (disk1), middle (disk 3) and bottom (disk 6) with five minor fault levels (1\% to $5 \%$ ).

The disk space variation fault level is defined as:

$\%$ DSV Fault level $=\frac{\text { Disk space variation length }(\Delta h)}{\text { Disk height }(h)} \times 100 \%$

The impact of the investigated DSV fault levels within the top, middle and bottom locations of the $\mathrm{HV}$ winding on the conventional FRA signature is shown in Fig. 11. Similar to the AD case study, minor DSV are extremely hard to be identified and quantified using conventional FRA signature.

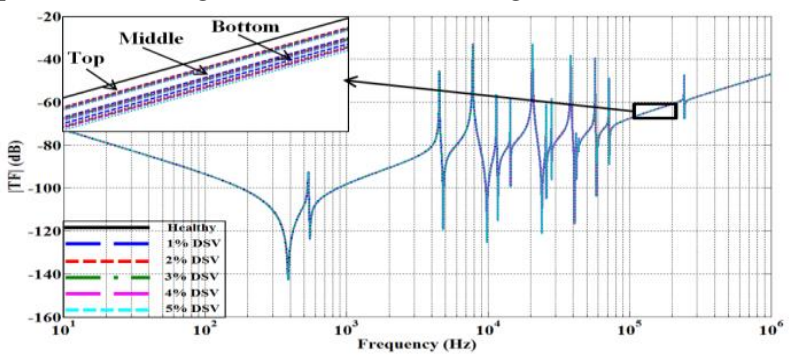

Fig. 11. Impact of DSV on 10kVA HV winding conventional FRA signature (b) (c) 

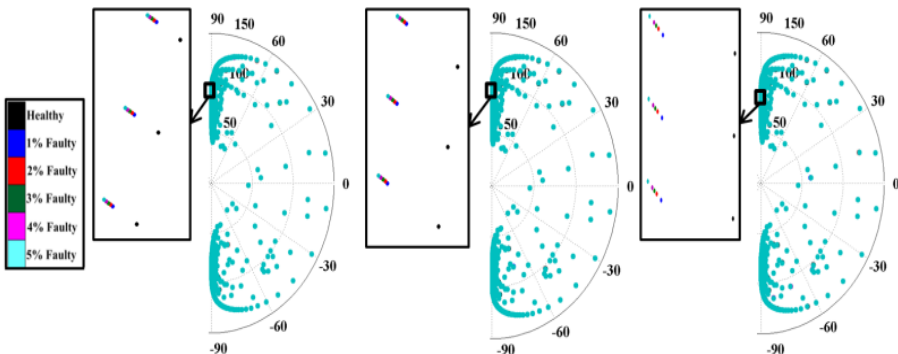

Fig. 12. Impact of DSV on 10kVA HV winding polar plot signature: (a) top, (b) middle and (c) bottom

The impacts of DSV fault of the same levels and locations on the proposed polar plot signature are obtained as shown in Fig. 12 that are processed using the developed DIP techniques to extract the geometric dimension features and the 11 combined features of invariant moment and texture analysis techniques, as listed in Tables V and VI, respectively.

TABLE V

Geometric dimension features of 10kVA transformer HV winding DSV fault

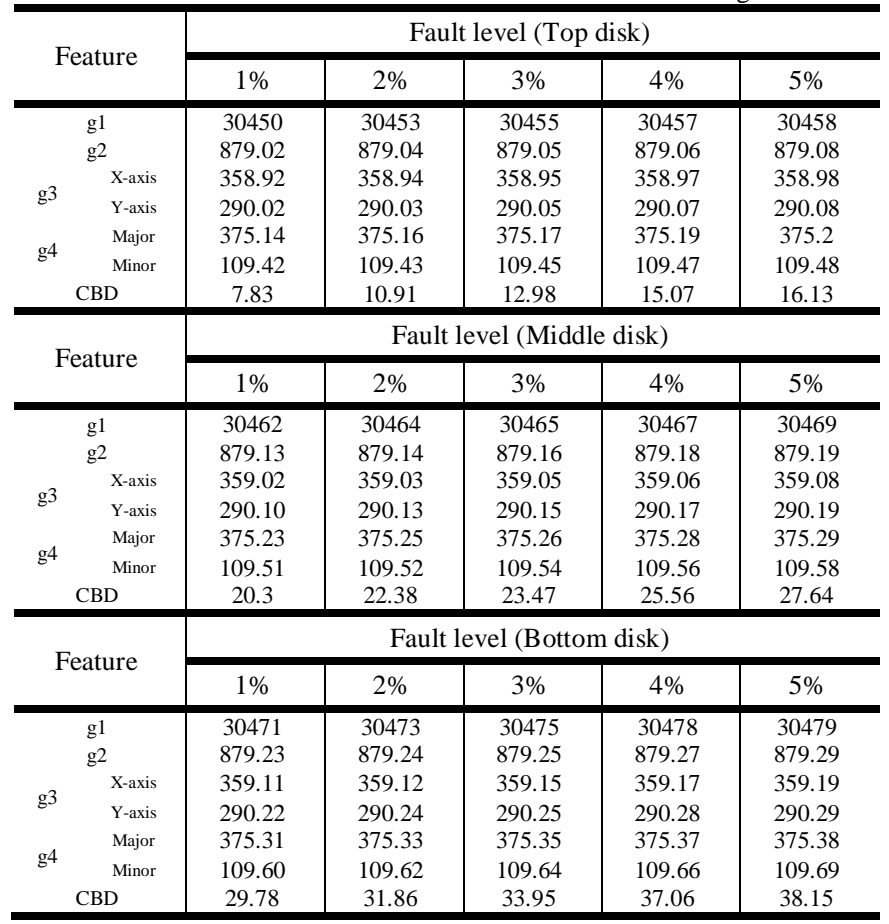

TABLE VI

The 11 extracted features of 10kVA transformer HV winding DSV fault

\begin{tabular}{|c|c|c|c|c|c|}
\hline \multirow{2}{*}{ Feature } & \multicolumn{5}{|c|}{ Fault level (Top disk) } \\
\hline & $1 \%$ & $2 \%$ & $3 \%$ & $4 \%$ & $5 \%$ \\
\hline 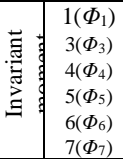 & $\begin{array}{c}0.2921 \\
0.0017 \\
-0.0052 \\
0.6357 \\
0.0978 \\
0.5424 \\
\end{array}$ & $\begin{array}{c}0.2919 \\
0.0019 \\
-0.0055 \\
0.6356 \\
0.0976 \\
0.5426\end{array}$ & $\begin{array}{c}0.2918 \\
0.0021 \\
-0.0056 \\
0.6355 \\
0.0975 \\
0.5428 \\
\end{array}$ & $\begin{array}{c}0.2917 \\
0.0022 \\
-0.0058 \\
0.6354 \\
0.0973 \\
0.5429\end{array}$ & $\begin{array}{c}0.2916 \\
0.0023 \\
-0.0059 \\
0.6353 \\
0.0972 \\
0.5431 \\
\end{array}$ \\
\hline 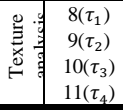 & $\begin{array}{l}0.0781 \\
1.9608 \\
1.8220 \\
0.4863 \\
\end{array}$ & $\begin{array}{l}0.0783 \\
1.9607 \\
1.8219 \\
0.4859 \\
\end{array}$ & $\begin{array}{l}0.0784 \\
1.9605 \\
1.8217 \\
0.4855 \\
\end{array}$ & $\begin{array}{l}0.0786 \\
1.9603 \\
1.8216 \\
0.4847 \\
\end{array}$ & $\begin{array}{l}0.0788 \\
1.9602 \\
1.8215 \\
0.4842 \\
\end{array}$ \\
\hline RMS & 0.86340959 & 0.86334767 & 0.86324911 & 0.863143 & 0.863081 \\
\hline IED & 0.00163095 & 0.002130728 & 0.002666458 & 0.003524 & 0.004133 \\
\hline \multirow{2}{*}{ Feature } & \multicolumn{5}{|c|}{ Fault level (Middle disk) } \\
\hline & $1 \%$ & $2 \%$ & $3 \%$ & $4 \%$ & $5 \%$ \\
\hline 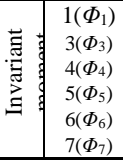 & $\begin{array}{c}0.2897 \\
0.0025 \\
-0.0061 \\
0.6348 \\
0.0969 \\
0.5434 \\
\end{array}$ & $\begin{array}{c}0.2892 \\
0.0026 \\
-0.0062 \\
0.6346 \\
0.0968 \\
0.5436 \\
\end{array}$ & $\begin{array}{c}0.2886 \\
0.0027 \\
-0.0064 \\
0.6345 \\
0.0966 \\
0.5437 \\
\end{array}$ & $\begin{array}{c}0.2881 \\
0.0028 \\
-0.0065 \\
0.6344 \\
0.0965 \\
0.5439 \\
\end{array}$ & $\begin{array}{c}0.2877 \\
0.0029 \\
-0.0066 \\
0.6341 \\
0.0963 \\
0.5442 \\
\end{array}$ \\
\hline $8\left(\tau_{1}\right)$ & 0.0793 & 0.0794 & 0.0797 & 0.0798 & 0.0799 \\
\hline
\end{tabular}

\begin{tabular}{|c|c|c|c|c|c|}
\hline $\begin{array}{c}9\left(\tau_{2}\right) \\
10\left(\tau_{3}\right) \\
11\left(\tau_{4}\right)\end{array}$ & $\begin{array}{l}1.9598 \\
1.8212 \\
0.4839\end{array}$ & $\begin{array}{c}1.9596 \\
1.821 \\
0.4837\end{array}$ & $\begin{array}{l}1.9595 \\
1.8208 \\
0.4836\end{array}$ & $\begin{array}{l}1.9593 \\
1.8206 \\
0.4834\end{array}$ & $\begin{array}{l}1.9592 \\
1.8202 \\
0.4832\end{array}$ \\
\hline RMS & 0.862852 & 0.862745 & 0.862662 & 0.862562 & 0.862438 \\
\hline IED & 0.005696 & 0.006332 & 0.006994 & 0.007633 & 0.008311 \\
\hline \multirow{2}{*}{ Feature } & \multicolumn{5}{|c|}{ Fault level (Bottom disk) } \\
\hline & $1 \%$ & $2 \%$ & $3 \%$ & $4 \%$ & $5 \%$ \\
\hline $\begin{array}{l}1\left(\Phi_{1}\right) \\
3\left(\Phi_{3}\right) \\
4\left(\Phi_{4}\right) \\
5\left(\Phi_{5}\right) \\
6\left(\Phi_{6}\right) \\
7\left(\Phi_{7}\right)\end{array}$ & $\begin{array}{c}0.2865 \\
0.0031 \\
-0.0068 \\
0.6337 \\
0.0957 \\
0.5446\end{array}$ & $\begin{array}{c}0.2854 \\
0.0032 \\
-0.0069 \\
0.6335 \\
0.0956 \\
0.5447\end{array}$ & $\begin{array}{c}0.2837 \\
0.0034 \\
-0.0071 \\
0.6334 \\
0.0954 \\
0.5449\end{array}$ & $\begin{array}{c}0.2831 \\
0.0035 \\
-0.0072 \\
0.6332 \\
0.0952 \\
0.5452\end{array}$ & $\begin{array}{c}0.2819 \\
0.0036 \\
-0.0074 \\
0.6330 \\
0.0951 \\
0.5453\end{array}$ \\
\hline 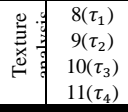 & $\begin{array}{l}0.0803 \\
1.9587 \\
1.8197 \\
0.4829 \\
\end{array}$ & $\begin{array}{l}0.0805 \\
1.9586 \\
1.8196 \\
0.4827\end{array}$ & $\begin{array}{l}0.0806 \\
1.9584 \\
1.8194 \\
0.4826 \\
\end{array}$ & $\begin{array}{l}0.0809 \\
1.9582 \\
1.8193 \\
0.4824 \\
\end{array}$ & $\begin{array}{l}0.0811 \\
1.9581 \\
1.8191 \\
0.4821 \\
\end{array}$ \\
\hline RMS & 0.862181 & 0.862091 & 0.861959 & 0.861875 & 0.861758 \\
\hline IED & 0.009898 & 0.010932 & 0.012455 & 0.013274 & 0.014516 \\
\hline
\end{tabular}

These tables indicate that the extracted features of this case study are characterized by a similar trend to that of the $\mathrm{AD}$ fault where the CBD and IED are increasing while the RMS metric is decreasing with the increase in DSV fault level.

Results also show that the value of the CBD and IED metrics is increasing, while RMS is decreasing when the fault moves toward the bottom of the winding as shown in Fig. 13 which also shows the proposed threshold limits that could be used to identify the location and quantify the level of minor DSV faults. Fig. 13 reveals the ability of the proposed approach to identify the DSV fault location within the HV winding without overlapping among the obtained metrics trends. Although results of the DIP technique show the same trend for the two investigated fault types (AD and DSV), it can be observed that for the same fault level, the value of the CBD and IED is higher in case of DSV than that of the AD while the RMS value is less for DSV fault. This could be used as a key to distinguish the two types of faults.
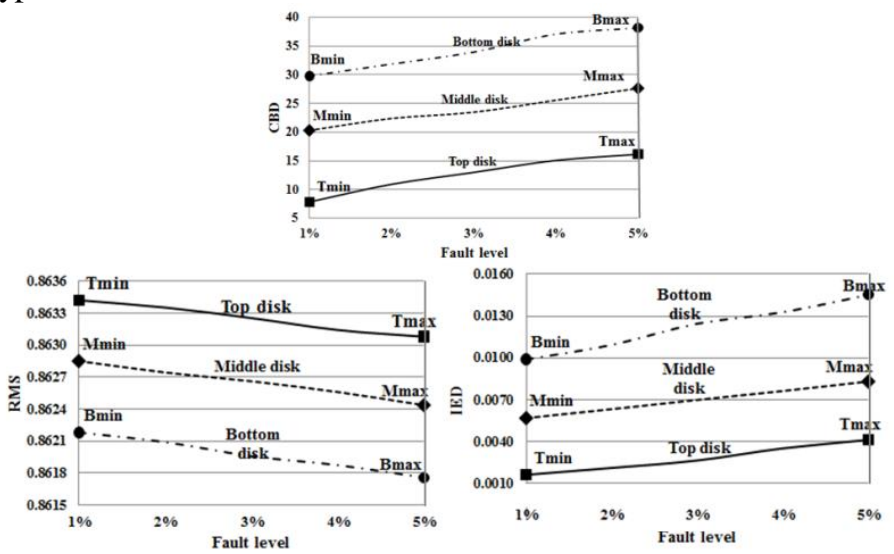

Fig. 13. CBD, RMS, and IED for DSV at different locations of the 10kVA HV winding

B. Case study 2: 40MVA transformer

The impact of the transformer rating, size and winding structure on the proposed technique is investigated by simulating the same fault levels and locations studied above on the 40MVA transformer.

\section{Axial displacement fault}

$\mathrm{AD}$ fault with five minor levels (1\% to $5 \%$ ) is simulated using FEA on phase A of the HV and LV windings of the 40MVA transformer and the FRA signature is obtained for each fault level and compared with the transformer healthy signature (magnitude of the TF) that is shown in Fig. 3 (a). Similar to the 
previous case study, the impact of minor $\mathrm{AD}$ fault levels within the LV and HV windings of the 40MVA are found to be extremely hard to detect using the current conventional FRA interpretation approach. The proposed polar plots are obtained and analyzed using the developed DIP techniques for all investigated fault levels to extract 15 features of the polar plot image, as given in Tables VII and VIII. As can be noticed in these tables, the trend of the extracted features of the investigated $\mathrm{AD}$ fault levels is similar to that of the $10 \mathrm{kVA}$ transformer however; the extracted features are larger in case of the 40MVA transformer. The threshold minimum and maximum levels of the three calculated metrics are illustrated in Fig. 14 which shows that while the CBD and IED metrics are increasing with the increase in fault level, the RMS metric is decreasing.

TABLE VII

Geometric dimension features of 40MVA transformer AD fault

\begin{tabular}{|c|c|c|c|c|c|c|}
\hline \multirow{2}{*}{\multicolumn{2}{|c|}{ Feature }} & \multicolumn{5}{|c|}{ Fault level (HV winding) } \\
\hline & & $1 \%$ & $2 \%$ & $3 \%$ & $4 \%$ & $5 \%$ \\
\hline \multirow{2}{*}{\multicolumn{2}{|c|}{$\begin{array}{l}\text { g1 } \\
\text { g2 }\end{array}$}} & 67226 & 67432 & 67588 & 67694 & 67791 \\
\hline & & 1895.09 & 1895.28 & 1895.37 & 1895.64 & 1895.75 \\
\hline & $\mathrm{X}$-axis & 745.34 & 746.52 & 747.67 & 748.28 & 749.73 \\
\hline & Y-axis & 622.76 & 623.86 & 624.37 & 625.18 & 626.59 \\
\hline & Major & 846.28 & 846.46 & 846.69 & 847.22 & 847.57 \\
\hline & Minor & 210.14 & 210.39 & 210.58 & 210.74 & 210.96 \\
\hline & & 1296.79 & 1505.69 & 1663.86 & 1772.24 & 1872.78 \\
\hline \multirow{2}{*}{\multicolumn{2}{|c|}{ Feature }} & \multicolumn{5}{|c|}{ Fault level (LV winding) } \\
\hline & & $1 \%$ & $2 \%$ & $3 \%$ & $4 \%$ & $5 \%$ \\
\hline \multirow{2}{*}{\multicolumn{2}{|c|}{$\begin{array}{l}\mathrm{g} 1 \\
\mathrm{~g} 2\end{array}$}} & 48854 & 48886 & 48917 & 48967 & 48993 \\
\hline & & 1476.13 & 1476.32 & 1476.48 & 1476.67 & 1476.92 \\
\hline & $\mathrm{X}$-axis & 675.07 & 675.48 & 675.83 & 676.27 & 676.85 \\
\hline & Y-axis & 565.41 & 565.52 & 565.63 & 565.77 & 565.94 \\
\hline & Major & 645.34 & 646.27 & 647.15 & 648.52 & 649.86 \\
\hline & Minor & 129.16 & 129.37 & 129.46 & 129.71 & 129.83 \\
\hline & CBD & 1176.95 & 1210.8 & 1243.39 & 1295.78 & 1324.24 \\
\hline
\end{tabular}

TABLE VIII

The 11 extracted features of 40MVA transformer AD fault

\begin{tabular}{|c|c|c|c|c|c|}
\hline \multirow{2}{*}{ Feature } & \multicolumn{5}{|c|}{ Fault level (HV winding) } \\
\hline & $1 \%$ & $2 \%$ & $3 \%$ & $4 \%$ & $5 \%$ \\
\hline 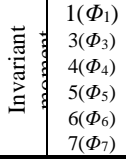 & $\begin{array}{c}0.5992 \\
0.0124 \\
-0.0458 \\
3.1684 \\
1.0895 \\
2.5952 \\
\end{array}$ & $\begin{array}{c}0.5974 \\
0.0176 \\
-0.0468 \\
3.1675 \\
1.0884 \\
2.5968 \\
\end{array}$ & $\begin{array}{c}0.5958 \\
0.0226 \\
-0.0473 \\
3.1664 \\
1.0876 \\
2.5976 \\
\end{array}$ & $\begin{array}{c}0.5931 \\
0.0289 \\
-0.0482 \\
3.1652 \\
1.0861 \\
2.5985\end{array}$ & $\begin{array}{c}0.5907 \\
0.0319 \\
-0.0494 \\
3.1638 \\
1.0838 \\
2.5992\end{array}$ \\
\hline 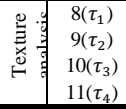 & $\begin{array}{l}0.0643 \\
1.9624 \\
1.8625 \\
0.5121 \\
\end{array}$ & $\begin{array}{l}0.0657 \\
1.9622 \\
1.8621 \\
0.5118 \\
\end{array}$ & $\begin{array}{l}0.0662 \\
1.9617 \\
1.8618 \\
0.5116 \\
\end{array}$ & $\begin{array}{l}0.0673 \\
1.9611 \\
1.8615 \\
0.5114 \\
\end{array}$ & $\begin{array}{l}0.0684 \\
1.9605 \\
1.8611 \\
0.5111 \\
\end{array}$ \\
\hline RMS & 1.534702 & 1.534581 & 1.534301 & 1.533930 & 1.533434 \\
\hline IED & 0.042565 & 0.046361 & 0.049857 & 0.055179 & 0.059580 \\
\hline \multirow{2}{*}{ Feature } & \multicolumn{5}{|c|}{ Fault level/ LV winding } \\
\hline & $1 \%$ & $2 \%$ & $3 \%$ & $4 \%$ & $5 \%$ \\
\hline 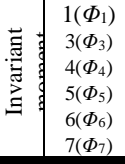 & \begin{tabular}{c|}
0.8076 \\
0.0157 \\
-0.0414 \\
5.2764 \\
2.3386 \\
4.3237 \\
\end{tabular} & $\begin{array}{c}0.8012 \\
0.0189 \\
-0.0422 \\
5.2742 \\
2.3375 \\
4.3256 \\
\end{array}$ & $\begin{array}{c}0.7986 \\
0.0208 \\
-0.0445 \\
5.2731 \\
2.3364 \\
4.3282 \\
\end{array}$ & $\begin{array}{c}0.7932 \\
0.0235 \\
-0.0457 \\
5.2722 \\
2.3342 \\
4.3327 \\
\end{array}$ & $\begin{array}{c}0.7907 \\
0.0276 \\
-0.0467 \\
5.2708 \\
2.3321 \\
4.3358 \\
\end{array}$ \\
\hline 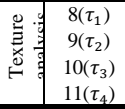 & $\begin{array}{l}0.0559 \\
1.9592 \\
1.8679 \\
0.5287 \\
\end{array}$ & $\begin{array}{l}0.0589 \\
1.9581 \\
1.8663 \\
0.5276 \\
\end{array}$ & $\begin{array}{l}0.0612 \\
1.9573 \\
1.8658 \\
0.5252 \\
\end{array}$ & $\begin{array}{l}0.0656 \\
1.9555 \\
1.8631 \\
0.5245 \\
\end{array}$ & $\begin{array}{l}0.0687 \\
1.9524 \\
1.8617 \\
0.5231 \\
\end{array}$ \\
\hline RMS & 2.340710 & 2.340067 & 2.339962 & 2.339837 & 2.339454 \\
\hline IED & 0.032238 & 0.038028 & 0.042318 & 0.050006 & 0.057177 \\
\hline
\end{tabular}

\section{Disk space variation fault}

DSV with minor fault levels are simulated within various locations including top (disk 1), middle (disk 5) and bottom (disk 10) of the 40MVA transformer HV winding. Polar plots are obtained and analyzed using the developed DIP techniques. Extracted features for this case study are given in Tables IX and
$X$. The three metrics, CBD, RMS and IED, are calculated to identify the threshold minimum and maximum limits for each level/location of DSV fault within the HV winding as shown in Fig. 15 which reveals the ability of the proposed approach to detect DSV fault level and location without overlapping among the proposed limits. Similar to the analysis of the DSV fault for the $10 \mathrm{kVA}$ transformer, the same trend for the calculated metrics is observed for each level and location with larger values in case of the 40MVA transformer.

It is worth mentioning that, in case of overlapped values in any of the calculated metrics, the DSV fault location can be still identified within the top, bottom or middle section of the winding. The error in identifying the exact faulty disk within the winding will be very small as the height of each section is relatively small $(14.14 \mathrm{~cm}$ in case of $10 \mathrm{kVA}$ transformer and $40 \mathrm{~cm}$ in case of $40 \mathrm{MVA}$ transformer).
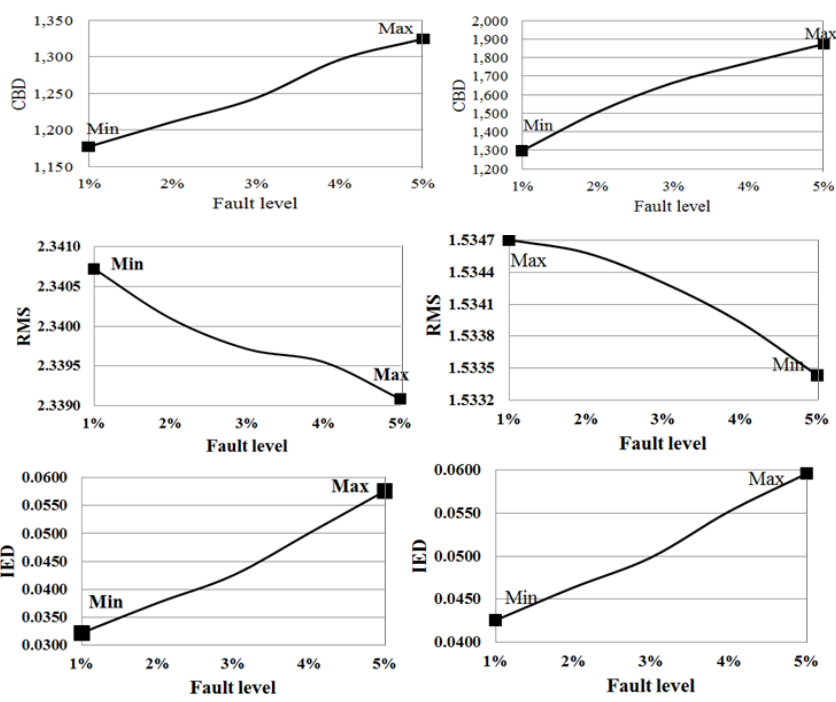

Fig. 14. CBD, RMS and IED trends for 40MVA AD: (a) LV and (b) HV

TABLE IX

Geometric dimension features of 40MVA transformer HV winding DSV fault

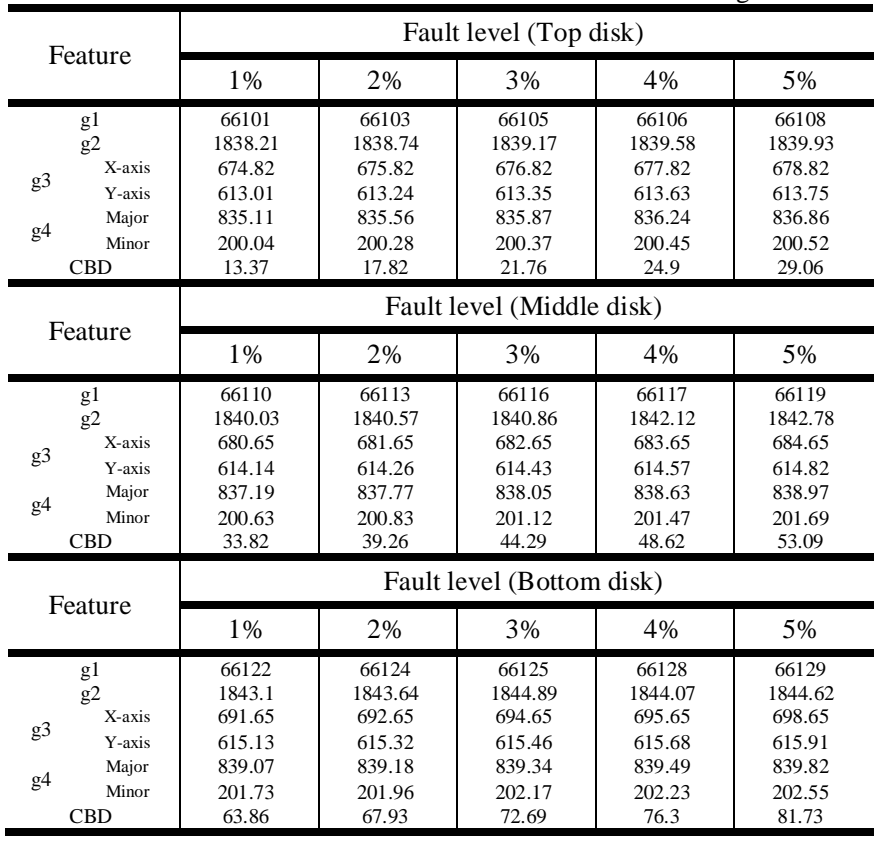



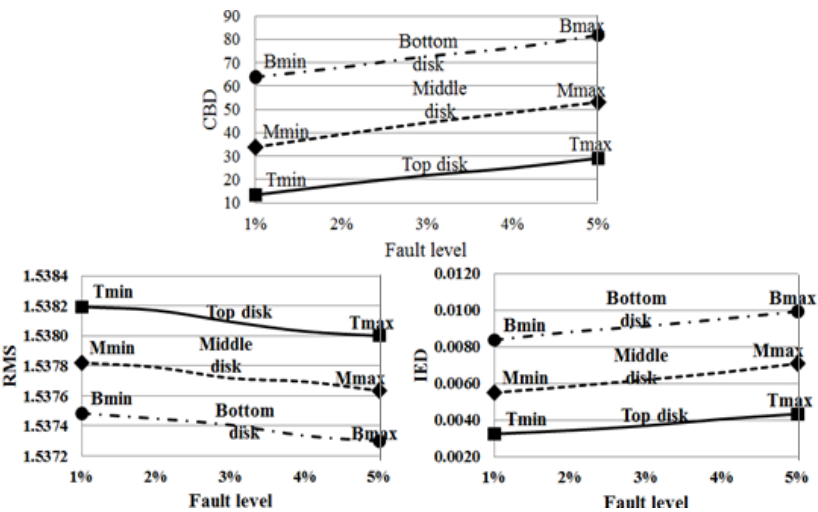

Fig. 15. CBD, RMS and IED for DSV at different locations of the 40MVA HV winding

TABLE $X$

The 11 extracted features of 40MVA transformer HV winding DSV fault

\begin{tabular}{|c|c|c|c|c|c|}
\hline \multirow{2}{*}{ Feature } & \multicolumn{5}{|c|}{ Fault level (Top disk) } \\
\hline & $1 \%$ & $2 \%$ & $3 \%$ & $4 \%$ & $5 \%$ \\
\hline 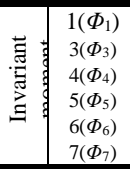 & $\begin{array}{l}0.6205 \\
0.0072 \\
-0.0351 \\
3.1859 \\
1.0938 \\
2.5772 \\
\end{array}$ & $\begin{array}{c}0.6204 \\
0.0073 \\
-0.0352 \\
3.1858 \\
1.0937 \\
2.5774 \\
\end{array}$ & $\begin{array}{c}0.6203 \\
0.0074 \\
-0.0353 \\
3.1856 \\
1.0935 \\
2.5775 \\
\end{array}$ & $\begin{array}{c}0.6202 \\
0.0075 \\
-0.0355 \\
3.1854 \\
1.0933 \\
2.5776 \\
\end{array}$ & $\begin{array}{c}0.6201 \\
0.0076 \\
-0.0356 \\
3.1853 \\
1.0931 \\
2.5778 \\
\end{array}$ \\
\hline 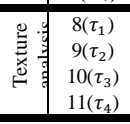 & $\begin{array}{l}0.0575 \\
1.9712 \\
1.8662 \\
0.5293 \\
\end{array}$ & $\begin{array}{l}0.0576 \\
1.9711 \\
1.8661 \\
0.5292 \\
\end{array}$ & $\begin{array}{c}0.0577 \\
1.9709 \\
1.866 \\
0.5291 \\
\end{array}$ & $\begin{array}{c}0.0578 \\
1.9708 \\
1.8659 \\
0.529 \\
\end{array}$ & $\begin{array}{l}0.0579 \\
1.9707 \\
1.8658 \\
0.5289 \\
\end{array}$ \\
\hline RMS & 1.538193 & 1.538169 & 1.538093 & 1.538029 & 1.537999 \\
\hline IED & 0.003231 & 0.003428 & 0.003685 & 0.004044 & 0.004326 \\
\hline \multirow{2}{*}{ Feature } & \multicolumn{5}{|c|}{ Fault level (Middle disk) } \\
\hline & $1 \%$ & $2 \%$ & $3 \%$ & $4 \%$ & $5 \%$ \\
\hline 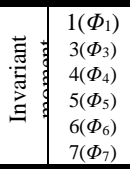 & $\begin{array}{c}0.6199 \\
0.0081 \\
-0.0362 \\
3.1848 \\
1.0928 \\
2.5782 \\
\end{array}$ & $\begin{array}{c}0.6198 \\
0.0082 \\
-0.0363 \\
3.1847 \\
1.0926 \\
2.5784 \\
\end{array}$ & $\begin{array}{c}0.6197 \\
0.0084 \\
-0.0364 \\
3.1845 \\
1.0925 \\
2.5785 \\
\end{array}$ & $\begin{array}{c}0.6196 \\
0.0085 \\
-0.0366 \\
3.1844 \\
1.0924 \\
2.5787 \\
\end{array}$ & $\begin{array}{c}0.6195 \\
0.0087 \\
-0.0368 \\
3.1842 \\
1.0922 \\
2.5789 \\
\end{array}$ \\
\hline 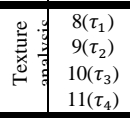 & $\begin{array}{l}0.0581 \\
1.9699 \\
1.8656 \\
0.5287 \\
\end{array}$ & $\begin{array}{l}0.0583 \\
1.9698 \\
1.8655 \\
0.5286 \\
\end{array}$ & $\begin{array}{l}0.0584 \\
1.9696 \\
1.8654 \\
0.5284 \\
\end{array}$ & $\begin{array}{l}0.0586 \\
1.9695 \\
1.8653 \\
0.5283 \\
\end{array}$ & $\begin{array}{l}0.0587 \\
1.9693 \\
1.8652 \\
0.5282 \\
\end{array}$ \\
\hline RMS & 1.53782 & 1.53779 & 1.537718 & 1.537695 & 1.537635 \\
\hline IED & 0.005492 & 0.005827 & 0.006196 & 0.006589 & 0.007080 \\
\hline \multirow{2}{*}{ Feature } & \multicolumn{5}{|c|}{ Fault level (Bottom disk) } \\
\hline & $1 \%$ & $2 \%$ & $3 \%$ & $4 \%$ & $5 \%$ \\
\hline 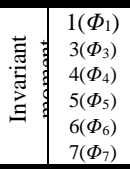 & $\begin{array}{c}0.6188 \\
0.0093 \\
-0.0372 \\
3.1839 \\
1.0917 \\
2.5793 \\
\end{array}$ & $\begin{array}{c}0.6187 \\
0.0095 \\
-0.0374 \\
3.1838 \\
1.0916 \\
2.5795 \\
\end{array}$ & $\begin{array}{c}0.6186 \\
0.0096 \\
-0.0375 \\
3.1837 \\
1.0915 \\
2.5796 \\
\end{array}$ & $\begin{array}{c}0.6184 \\
0.0097 \\
-0.0376 \\
3.1835 \\
1.0914 \\
2.5797 \\
\end{array}$ & $\begin{array}{c}0.6182 \\
0.0098 \\
-0.0377 \\
3.1834 \\
1.0912 \\
2.5799 \\
\end{array}$ \\
\hline 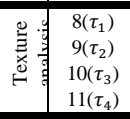 & $\begin{array}{l}0.0592 \\
1.9688 \\
1.8649 \\
0.5279 \\
\end{array}$ & $\begin{array}{l}0.0593 \\
1.9686 \\
1.8648 \\
0.5278 \\
\end{array}$ & $\begin{array}{l}0.0594 \\
1.9685 \\
1.8647 \\
0.5276 \\
\end{array}$ & $\begin{array}{l}0.0596 \\
1.9684 \\
1.8645 \\
0.5275 \\
\end{array}$ & $\begin{array}{l}0.0597 \\
1.9683 \\
1.8644 \\
0.5273 \\
\end{array}$ \\
\hline RMS & 1.537483 & 1.537448 & 1.537407 & 1.537335 & 1.537298 \\
\hline IED & 0.008360 & 0.008804 & 0.009119 & 0.009513 & 0.009920 \\
\hline
\end{tabular}

C. Case study 3: Combined AD and DSV faults

In this case study, the impact of a combined fault comprising AD and DSV faults when simultaneously occur within the HV winding on the proposed approach is investigated.

TABLE XI

DIP metrics of HV winding $5 \% \mathrm{AD}$, DSV and a combined AD and DSV (middle disk)

\begin{tabular}{c|c|c|c|c|c|c}
\hline \multirow{2}{*}{ Metric } & \multicolumn{3}{|c|}{ 10kVA } & \multicolumn{3}{c}{ 40MVA } \\
\cline { 2 - 7 } & AD & DSV & AD+DSV & AD & DSV & AD+DSV \\
\hline CBD & 139.77 & 27.64 & 483.37 & 1872.78 & 53.09 & 2359.12 \\
RMS & 0.845222 & 0.862438 & 0.807062 & 1.533434 & 1.537635 & 1.528061 \\
IED & 0.073257 & 0.008311 & 0.211304 & 0.059580 & 0.007080 & 0.226625 \\
\hline
\end{tabular}

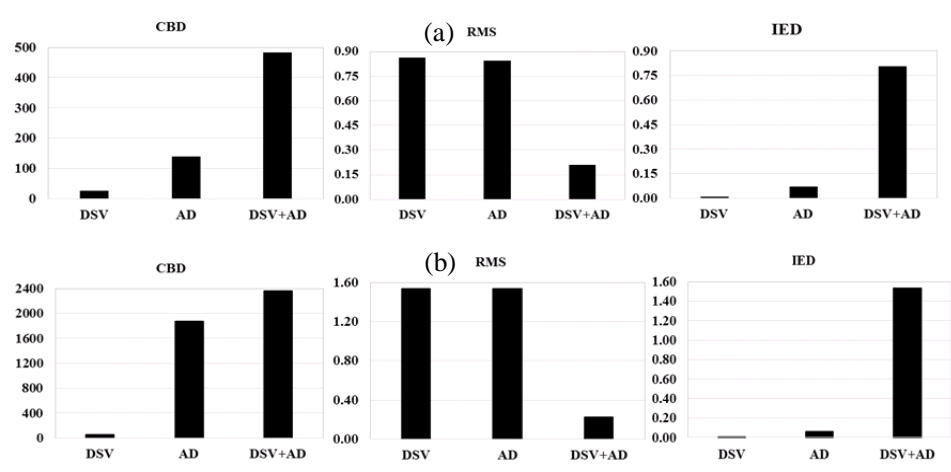

Fig. 16. CBD, RMS and IED for DSV, AD and combination of AD and DSV at $5 \%$ fault level within the middle disc of the HV winding: (a) 10kVA and (b) $40 \mathrm{MVA}$

FEA is used to simulate 5\% AD level along with 5\% DSV at the middle disk of the HV winding of both transformers. The polar plot signatures for the 10kVA and 40MVA transformers are obtained and processed using the developed DIP code to extract the 15 image features. These features are characterized by a similar trend as the previous cases and are used to calculate the three proposed metrics (listed in Table XI). It can be observed that the change in the CBD, RMS and IED parameters is significant when compared with the impact of each individual fault as shown in Fig. 16.

\section{Case study 4: Practical validation}

To investigate the practical feasibility of the proposed approach and validate the above simulation results, a practical 5\% AD fault is implemented on phase A of the LV winding of a scaleddown three phase delta-wye $7 \mathrm{kVA}, 440 / 55 \mathrm{~V}, 50 \mathrm{~Hz}$ dry type transformer. The FRA polar plot signature is measured through commercial frequency response analyzer for both healthy and faulty winding conditions. The hardware transformer model is also simulated using FEA to compare the practical and simulation results. The obtained polar plots using practical measurement and simulation analysis are processed using the DIP code to extract the proposed 15 image features which are used to calculate the three metrics. The trend of the three metrics CBD, RMS and IED is found to be similar to that of the 10kVA and 40MVA transformers with change in magnitudes as can be observed in Table XII.

TABLE XII

CBD, RMS and IED metrics for $5 \% \mathrm{AD}$ on phase $\mathrm{A}$ of the $7 \mathrm{kVA} \mathrm{LV}$ winding

\begin{tabular}{c|c|c}
\hline Feature & Practical & Simulation \\
\hline CBD & 9.22 & 9.25 \\
RMS & 2.913263 & 3.100786 \\
IED & 0.001959 & 0.002415 \\
\hline
\end{tabular}

VI.

\section{COMPARISON BETWEEN THE PROPOSED AND} STATISTICAL-BASED TECHNIQUES

As mentioned in the introduction section, interpretation of FRA magnitude signature based on calculating some statistical parameters such as correlation coefficient (CC) and absolute sum of logarithmic error (ASLE) are not reliable as stated in several publications in the literatures [7-12]. To prove this claim, the FRA magnitude signature of the 10kVA transformer, phase-A $\mathrm{HV}$ winding is processed to calculate the CC and ASLE based on the following equations: 


$$
\begin{aligned}
& \mathrm{CC}=\frac{\sum_{=1}^{n} X_{i} Y_{i}}{\sqrt{\sum_{i=1}^{n}\left[X_{i}\right]^{2} \sum_{i=1}^{n}\left[Y_{i}\right]^{2}}} \\
& \mathrm{ASLE}=\frac{\sum_{=1}^{n} Y_{i}-X_{i}}{n}
\end{aligned}
$$

where: $X_{i}$ and $Y_{i}$ are the $i^{\text {th }}$ elements of the reference and healthy signatures, respectively, whereas $n$ is the total number of selected points in the frequency response signature.

TABLE XIII

$\mathrm{CC}$ and ASLE for $\mathrm{AD}$ fault within the $\mathrm{HV}$ winding of the 10kVA transformer

\begin{tabular}{c|c|c|c|c|c}
\hline Fault level & CC & ASLE & CBD & RMS & IED \\
\hline $1 \%$ & 0.985 & 0.037 & 80.06 & 0.848081 & 0.058820 \\
$2 \%$ & 0.864 & 1.212 & 101.56 & 0.847514 & 0.061957 \\
$3 \%$ & 0.983 & 0.745 & 116.85 & 0.846757 & 0.065626 \\
$4 \%$ & 0.698 & 1.629 & 127.29 & 0.846234 & 0.068768 \\
$5 \%$ & 0.798 & 0.092 & 139.77 & 0.845222 & 0.073257 \\
\hline
\end{tabular}

Table XIII shows the calculated statistical indicators (CC and ASLE) along with the DIP metrics (CBD, RMS and IED) of the $\mathrm{AD}$ faults for five levels ( $1 \%$ to $5 \%$ ). While Table XIII shows a $\mathrm{CC}$ between the healthy and faulty signatures less than 1 (perfect correlation) for all fault levels, results are not consistent with the fault level e.g. 5\% fault level reveals higher CC than the $4 \%$ fault level. On the other hand, ASLE indicator should be zero when the two investigated signatures are perfectly correlated. As can be seen in the table, the ASLE indicator is not consistent with the fault level either as for fault level $5 \%$, the calculated value is less than that for fault levels $2 \%, 3 \%$ and $4 \%$. These results agree well with the previously published papers in the literature which reveal the inaccuracy of using these indicators in the interpretation process of the FRA signatures [11-13]. While these statistical indicators can be easily built within commercial frequency response analysers, fault identification and quantification based on these techniques is not reliable and is extremely hard. In contrary with the CC and ASLE indicators, the automated image features-based indicators; CBD, RMS and IED metrics reveal a consistent trend with the fault level as can be observed in Table XIII. Table XIV summarizes the advantageous of the proposed DIP-based technique over existing conventional and statistical FRA interpretation techniques.

TABLE XIV

\begin{tabular}{|c|c|c|c|}
\hline Characteristics & $\begin{array}{c}\text { Conventional FRA } \\
\text { approach }\end{array}$ & $\begin{array}{c}\text { Statistical FRA } \\
\text { approach }\end{array}$ & $\begin{array}{l}\text { Proposed DIP- } \\
\text { based approach }\end{array}$ \\
\hline FRA format & $\begin{array}{l}\text { FRA magnitude } \\
\text { signature }\end{array}$ & $\begin{array}{l}\text { FRA magnitude } \\
\text { signature }\end{array}$ & $\begin{array}{c}\text { FRA magnitude } \\
\text { and phase angle } \\
\text { signatures }\end{array}$ \\
\hline $\begin{array}{l}\text { Interpretation } \\
\text { process }\end{array}$ & Visual inspection & $\begin{array}{c}\text { Calculation of } \\
\text { various } \\
\text { statistical } \\
\text { parameters }\end{array}$ & $\begin{array}{l}\text { Extraction of } \\
\text { image features }\end{array}$ \\
\hline Accuracy & $\begin{array}{c}\text { Inconsistent; } \\
\text { depends on } \\
\text { personnel level of } \\
\text { expertise }\end{array}$ & $\begin{array}{l}\text { Low; depends on } \\
\text { the calculated } \\
\text { indicators }\end{array}$ & $\begin{array}{l}\text { High; depends } \\
\text { on the extracted } \\
\text { image features }\end{array}$ \\
\hline $\begin{array}{c}\text { Fault } \\
\text { quantification } \\
\text { /location }\end{array}$ & $\begin{array}{l}\text { Hard to quantify } \\
\text { fault level and } \\
\text { identify its } \\
\text { location }\end{array}$ & $\begin{array}{l}\text { Hard to quantify } \\
\text { fault level and } \\
\text { identify its } \\
\text { location }\end{array}$ & $\begin{array}{c}\text { Fault level / } \\
\text { location can } \\
\text { be quantified / } \\
\text { identified }\end{array}$ \\
\hline $\begin{array}{l}\text { Minor fault } \\
\text { detection }\end{array}$ & Undetectable & Undetectable & Detectable \\
\hline
\end{tabular}

Comparison of the proposed and current FRA interpretation approaches
Method

Manual

Automatic

Automatic

\section{IMPLEMENTATION OF THE PROPOSED TECHNIQUE}

The proposed technique can be easily built within any commercial frequency response analyzer and the FRA measurement along with the interpretation process can be automated onsite. Similar to current industry practice for conventional FRA technique, the reference dataset for healthy transformer can be identified through several options as listed below:

- FRA testing is strongly recommended for new transformers prior connecting it to the network and hence reference dataset can be easily identified. It is expected that a pool of reference dataset will be readily available for standard power transformers in the future.

- For old transformers, it is not recommended to obtain the healthy reference dataset from FRA practical measurement as these transformers may have already developed an internal fault. In this case, other comparison technique such as comparing polar plot image features of identically constructed transformers or a transformer phase-to-phase comparison has to be adopted for diagnosis. It is expected that all phases within the same transformer have almost identical polar plot features and any significant deviation among these features can be considered as an indication of fault.

- Alternatively, windings reference polar plot features can be obtained through the 3D finite element model of the investigated transformer as discussed in this paper. If the physical dimension and design data required for FEA are not available, polar plot can be obtained from the transformer high frequency model. The electrical parameters of this model can be estimated based on evolutionary algorithms using nonphysical dimension data such as the magnitude and phase angle of the voltage and current that may be acquired from transformer nameplate data [28-30].

\section{CONCLUSION}

This paper presents a new interpretation approach for power transformer frequency response analysis based on polar plot and digital image processing techniques. In contrary with the current conventional approach that relies on the level of personnel expertise which may lead to different conclusions for the same FRA signature, the proposed technique can be implemented within any commercial frequency response analyzer to automate and standardize the whole process. Moreover, the proposed technique is able to quantify minor fault levels and identify its location which is considered as the main drawback of the conventional FRA technique. Digital image processing code is developed to extract unique geometric dimensions, invariant moment and texture analysis features from the proposed polar plot signature. The extracted features are used to calculate three metrics; city-block distance, root mean square and the imageEuclidean distance to determine the threshold minimum and maximum levels of axial displacement and disk space variation of two transformers of different ratings, sizes and winding structures. Simulation results are validated through practical application of the proposed approach on a scaled-down transformer. While the feasibility of the proposed technique is 
validated through its applications to detect $A D$ and DSV, the approach can be extended to detect other mechanical faults within power transformers.

\section{APPENDDIX}

TABLE A-I

Equivalent circuit parameters for the investigated transformers

\begin{tabular}{c|c|c|c|c}
\hline \multirow{2}{*}{$\begin{array}{c}\text { Transformer } \\
\text { parameters }\end{array}$} & \multicolumn{2}{|c|}{ 10kVA } & \multicolumn{2}{c}{ 40MVA } \\
\cline { 2 - 5 } & HV & LV & HV & LV \\
\hline$L_{s}[\mu \mathrm{H}], R_{s}[\Omega]$ & 40,1 & $20,0.5$ & 10,1 & $10.5,0.25$ \\
$C_{s h}[p \mathrm{~F}]$ & 2.35 & 37.27 & 393.4 & 127.67 \\
$G_{s h}[\mu \mathrm{S}]$ & 6.45 & 260.89 & 196.7 & 63.835 \\
$C_{o}[p \mathrm{~F}]$ & 20 & 718 & 61.192 & 115.53 \\
$G_{o}[\mu \mathrm{S}]$ & 140 & 5026 & 30.596 & 57.765 \\
\hline$C_{H L}[p \mathrm{~F}], G_{H L}[\mu \mathrm{S}]$ & \multicolumn{2}{|c|}{50,350} & \multicolumn{2}{c}{$89.283,44.65$} \\
\hline
\end{tabular}

TABLE A-II

Geometrical features equations

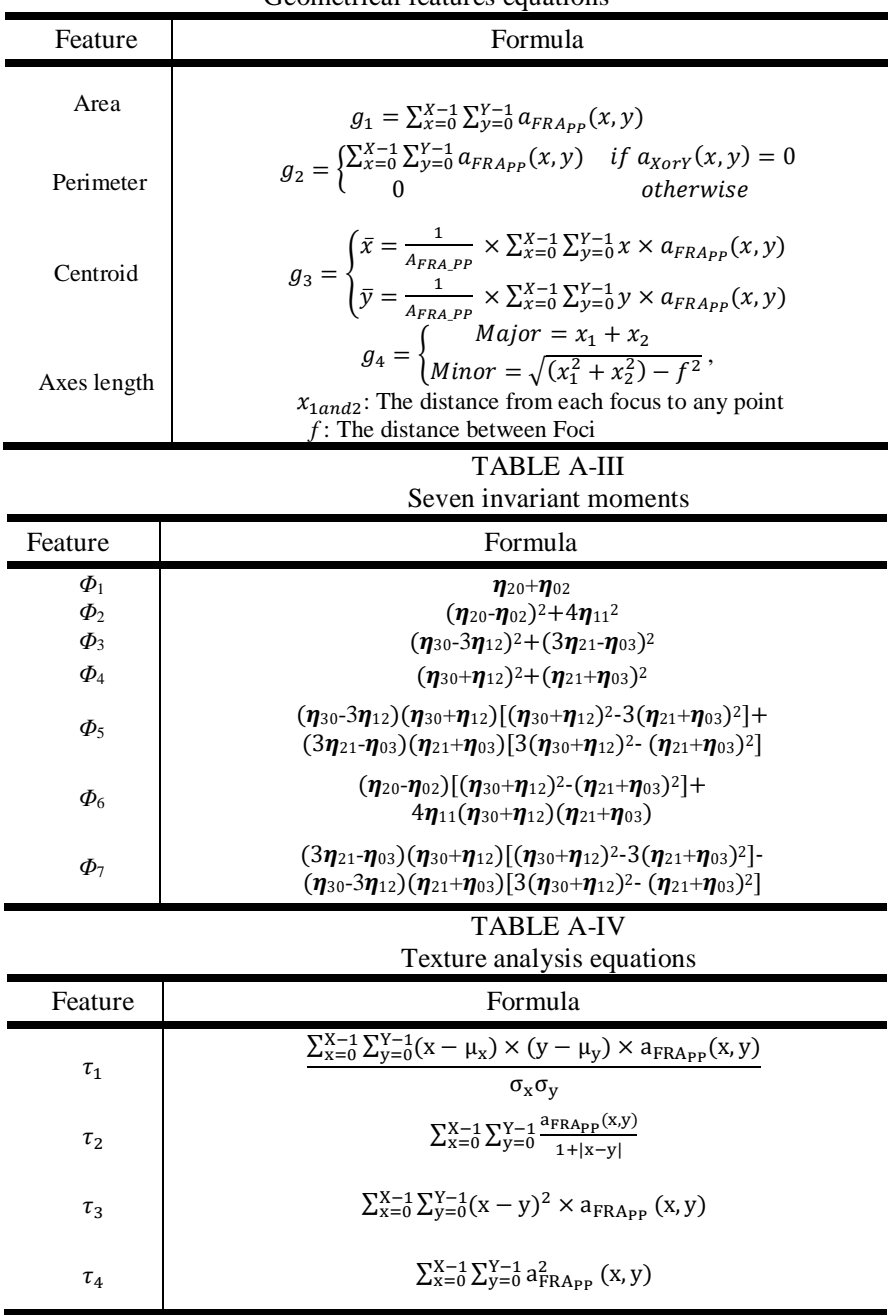

\section{REFERENCES}

[1] S. D. Mitchell and J. S. Welsh, "Modeling Power Transformers to Support the Interpretation of Frequency-Response Analysis," Power Delivery, IEEE Transactions on, vol. 26, pp. 2705-2717, 2011.

[2] E. Rahimpour and S. Tenbohlen, "Experimental and theoretical investigation of disc space variation in real high-voltage windings using transfer function method," Electric Power Applications, IET, vol. 4, pp. 451-461, 2010.

[3] A. Abu-Siada and S. Islam, "A Novel Online Technique to Detect Power Transformer Winding Faults," Power Delivery, IEEE Transactions on, vol. 27, pp. $849-857,2012$
[4] A. Abu-Siada, N. Hashemnia, S. Islam, and M. A. S. Masoum, "Understanding power transformer frequency response analysis signatures," Electrical Insulation Magazine, IEEE, vol. 29, pp. 48-56, 2013.

[5] M. Wang, A. J. Vandermaar, and K. D. Srivastava, "Improved detection of power transformer winding movement by extending the FRA high frequency range," IEEE Transactions on Power Delivery, vol. 20, pp. 1930-1938, 2005.

[6] D. A. K. Pham, T. M. T., H. Borsi, and E. Gockenbach, "A new method for purposes of failure diagnostics and FRA interpretation applicable to power transformers," Dielectrics and Electrical Insulation, IEEE Transactions on, vol. 20, pp. 2026-2034, 2013

[7] O. Aljohani and A. Abu-Siada, "Minimum detection of power transformer short circuit fault using frequency response analysis," in Power Engineering Conference (AUPEC), 2015 Australasian Universities, 2015, pp. 1-5.

[8] V. Behjat and M. Mahvi, "Statistical approach for interpretation of power transformers frequency response analysis results," IET Science, Measurement \& Technology, vol. 9, pp. 367-375, 2015.

[9] S. A. Ryder, "Methods for comparing frequency response analysis measurements," in Electrical Insulation, 2002. Conference Record of the 2002 IEEE International Symposium on, 2002, pp. 187-190.

[10] K. Jong-Wook, P. ByungKoo, J. Seung Cheol, K. Sang Woo, and P. PooGyeon, "Fault diagnosis of a power transformer using an improved frequency-response analysis," IEEE Transactions on Power Delivery, vol. 20, pp. 169-178, 2005.

[11] V. Behjat, M. Mahvi, and E. Rahimpour, "New statistical approach to interpret power transformer frequency response analysis: non-parametric statistical methods," IET Science, Measurement \& Technology, vol. 10, pp. 364-369, 2016.

[12] K. P. Badgujar, M. Maoyafikuddin, and S. V. Kulkarni, "Alternative statistical techniques for aiding SFRA diagnostics in transformers," IET Generation, Transmission \& Distribution, vol. 6, pp. 189-198, 2012.

[13] M. F. M. Yousof, C. Ekanayake, and T. K. Saha, "Frequency response analysis to investigate deformation of transformer winding," IEEE Transactions on Dielectrics and Electrical Insulation, vol. 22, pp. 2359-2367, 2015.

[14] H. Zhang, B. Yang, W. Xu, S. Wang, G. Wang, Y. Huangfu, et al., "Dynamic Deformation Analysis of Power Transformer Windings in Short-Circuit Fault by FEM," IEEE Transactions on Applied Superconductivity, vol. 24, pp. 1-4, 2014

[15] A. HyunMo, L. Ji-Yeon, K. Joong-Kyoung, O. Yeon-Ho, J. Sang, and H. SungChin, "Finite-Element Analysis of Short-Circuit Electromagnetic Force in Power Transformer," Industry Applications, IEEE Transactions on, vol. 47, pp. 12671272,2011

[16] Y. Bertrand and L. Hoang, "Vegetable Oils As Substitute For Mineral Insulating Oils In Medium-Voltage Equipment," CIGRE, France2007.

[17] N. Hashemnia, A. Abu-Siada, and S. Islam, "Improved power transformer winding fault detection using FRA diagnostics part 1: axial displacement simulation," Dielectrics and Electrical Insulation, IEEE Transactions on, vol. 22, pp. 556-563, 2015.

[18] N. Hashemnia, A. Abu-Siada, and S. Islam, "Improved power transformer winding fault detection using FRA diagnostics part 2: radial deformation simulation," Dielectrics and Electrical Insulation, IEEE Transactions on, vol. 22, pp. 564-570, 2015.

[19] O. Aljohani and A. Abu-Siada, "Application of FRA polar plot technique to diagnose internal faults in power transformers," in PESGM Conference, 2014 IEEE, 2014, pp. 1-5.

[20] O. M. Aljohani and A. Abu-siada, "Impact of power transformer insulating mineral oil degradation on FRA polar plot," in Industrial Electronics (ISIE), 2015 IEEE 24th International Symposium on, 2015, pp. 567-572.

[21]A. R. E. W. Rafael C. Gonzalez, Digital image processing Upper Saddle River, N.J.: Upper Saddle River, N.J. : Pearson/Prentice Hall, 2008

[22] Z. Guangwen, Y. Lei, and Z. Fan, "An integrated color and texture feature extraction algorithm," in Computer Science and Network Technology (ICCSNT), 2012, pp. 733-737.

[23] C. Liang-Wei and L. Chao-Rong, "Invariant moment features for fingerprint recognition," in Wavelet Active Media Technology and Information Processing (ICCWAMTIP), 2013 10th International Computer Conference on, 2013, pp. 9194.

[24] R. E. W. Rafael C. Gonzalez, Steven L. Eddins, Digital Image processing using MATLAB 2nd ed.. ed. S.I.]: [S.I.] : Gatesmark Pub., 2009.

[25] J. Canny, "A Computational Approach to Edge Detection," IEEE Transactions on Pattern Analysis and Machine Intelligence, vol. PAMI-8, pp. 679-698, 1986.

[26] W. Mokrzycki and M. Samko, "Canny edge detection algorithm modification," in Computer Vision and Graphics, ed: Springer, 2012, pp. 533-540.

[27] V. Chandola, A. Banerjee, and V. Kumar, "Anomaly detection: A survey," ACM computing surveys (CSUR), vol. 41, p. 15, 2009.

[28] L. A. R. Tria, D. Zhang, and J. E. Fletcher, "High-Frequency Planar Transformer Parameter Estimation," IEEE Transactions on Magnetics, vol. 51, pp. 1-4, 2015

[29] M. I. Mossad, M. Azab, and A. Abu-Siada, "Transformer Parameters Estimation From Nameplate Data Using Evolutionary Programming Techniques," IEEE Transactions on Power Delivery, vol. 29, pp. 2118-2123, 2014.

[30] S.-D. Cho, "Three-phase Transformer Model and Parameter Estimation for ATP " Journal of Electrical Engineering \& Technology, vol. 1, 2006. 